FACULTY OF ECONOMICS AND APPLIED ECONOMIC SCIENCES

CENTER FOR ECONOMIC STUDIES

ENERGY, TRANSPORT \& ENVIRONMENT

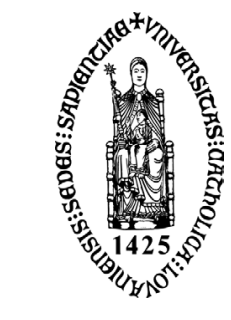

KATHOLIEKE UNIVERSITEIT

LEUVEN

WORKING PAPER SERIES

$n^{\circ}$ 2002-08

\title{
Environmental Pricing in Transport
}

\author{
Stef Proost \\ (K.U.Leuven-CES-ETE, Belgium) \\ Edward Calthrop \\ (K.U.Leuven-CES-ETE, Belgium)
}

August 2002

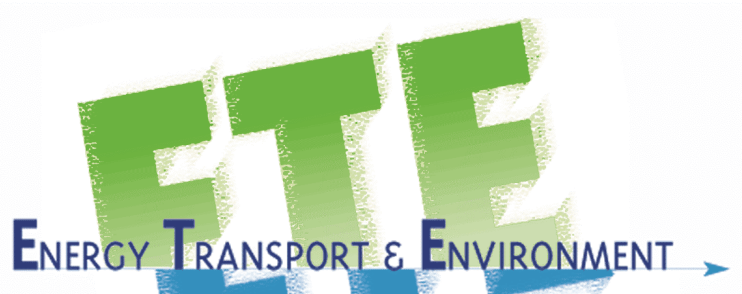

secretariat:

Isabelle Benoit

KULeuven-CES

Naamsestraat 69, B-3000 Leuven (Belgium)

tel: $\quad+32(0) 1632.66 .33$

fax: $\quad+32(0) 1632.69 .10$

e-mail: Isabelle.Benoit@econ.kuleuven.ac.be

http://www.kuleuven.ac.be/ete 


\title{
ENVIRONMENTAL PRICING IN TRANSPORT
}

Chapter for Handbook 4: Transport and the Environment

\author{
Edward Calthrop, Stef Proost*
}

\author{
Centre for Economic Studies \\ Catholic University of Leuven \\ Naamse straat 69 \\ 3000 Leuven \\ edward.calthrop@econ.kuleuven.ac.be \\ stef.proost@econ.kuleuven.ac.be \\ *corresponding author
}

running title 'Environmental pricing' 


\section{INTRODUCTION}

Transport activity is inextricably linked with environmental damage. Economists traditionally urge policy makers to adopt pricing solutions, in particular taxes, to reduce environmental damage rather than quantityrestrictions or standards. This chapter examines environmental pricing, defined broadly to include emission taxes, product taxes and subsidies and compares it to alternative approaches. We begin with a simple formal model to demonstrate the relative efficiency properties of pricing solutions, before highlighting some of the associated implementation problems. We then extend the scope and realism of the analysis by examining the choice between regulatory instruments in the presence of several market distortions. The basic case for environmental taxes, set at the correct level, is shown to remain.

It is impossible to cover all modes and all real world case studies of pricing in this text. Rather, we illustrate our central point in the context of air pollution from car use. However, as we stress in the concluding section, the essential insight from the model applies to a whole range of enviromental problems in the transport sector. Readers interested in surveys of practical experiences are referred to The Policy Issues chapters of Handbook 6. A general introduction to the choice of regulatory instruments to tackle environmental damage can be found in Kolstad (1999).

\section{RATIONALE FOR ENVIRONMENTAL TAXES}

Consider air pollution from a transport activity. Emissions can typically be reduced in two ways: through cleaner technology, which is supplied only at a higher resource cost, and through reducing the level of transport activity. As we shall see, one particular pricing instrument, a pollution tax, gives the correct incentive for efficient behaviour with respect to both of these margins.

We illustrate ideas with a simple model. Assume a perfectly competitive car market where the cost of supplying a single car kilometre (without pollution control equipment) is constant. We normalise this cost to zero - and hence all results below can be considered as net of the constant resource cost ${ }^{1}$. In the absence of pollution control, the monetary value of pollution damage per car kilometre is assumed constant ${ }^{2}$ and denoted by $d \in(0,1)$. The quantity of pollution control per car-kilometre, denoted by $z \in[0,1]$, is assumed continuous and is supplied at cost $(c / 2) z^{2}$ per kilometre $^{3}$. This parameterisation implies that the marginal cost of abatement is rising: more sophisticated and costly techniques are required to further decrease pollution. Abatement can take various forms: catalytic converters, cleaner fuels, lower speed etc. For ease, we assume $c=1$. In the presence of pollution abatement, the pollution damage per kilometre is assumed to equal $d(1-z)$. Finally, assume the marginal benefit of a kilometre of car use is given by a linear $45^{\circ}$ downward sloping function: $1-x$, where $\mathrm{x}$ is the quantity of car kilometres. Economists refer to this marginal benefit function as the inverse demand function. The demand function is then $x=1-p$ where $\mathrm{p}$ is

\footnotetext{
${ }^{1}$ This assumption just simplifies algebraic manipulations.

${ }^{2}$ We abstract from variations according to vehicle model or vintage, driving speed, cold-start ups etc.

${ }^{3}$ To keep matters simple, we abstract from issues of car ownership and only focus on car use.
} 
the consumer price: a consumer chooses a level of car use such that the marginal benefit equal the marginal private cost i.e. the price. This function is illustrated on Figure 1, where the price $\mathrm{p}^{\mathrm{N}}$ generates a consumption $x=1-p^{N} \equiv y^{N}$.

In order to compare environmental pricing with other instruments we first analyse a benchmark solution where a benevolent government can control the amount of pollution control and the quantity of car use directly. This defines the 'efficient outcome'. Next we allow the car users to choose freely the number of car kilometres and the degree of pollution abatement. Government can only control pollution indirectly: pricing instruments and technological standards can be used to alter driver behaviour which in turn alters the level of air pollution. An emissions tax - set at the correct level- results in drivers making choices that correspond to the efficient outcome. Other instruments typically fail.

\section{Efficient outcome}

Consider a benevolent government that is able to control directly the choice of pollution abatement, $z$, and the total number of kilometres driven, $y$. The objective function for the government is the total net benefit to society: i.e. the benefit of car use minus the costs to society. The total net benefit is the area under the marginal benefit curve in Figure 1 (the benefits of travel) gross of the environmental damage $(d(1-z))$ and the resource cost of using cleaner cars $\left(z^{2} / 2\right)$ :

$$
\int_{0}^{y}\left(1-x-d(1-z)-\frac{z^{2}}{2}\right) d x
$$

Maximising this objective with respect to the two control variables, $z$ and $y$, gives rise to two first order conditions ${ }^{4}$ :

$$
\begin{aligned}
& y: \quad y=1-d(1-z)-\frac{z^{2}}{2} \\
& z: \quad z=d
\end{aligned}
$$

Investment in pollution abatement equipment is optimal when the marginal cost of abatement, $\mathrm{z}$, per kilometre equals the marginal benefit in reduced air pollution damage, $\mathrm{d}$ per kilometre. Hence:

$$
z^{*}=d
$$

The optimal degree of abatement is not necessarily 100\%: the marginal cost of pollution abatement may be too high compared to the marginal damage avoided to justify a high degree of pollution abatement. Substituting (0.3) into the condition for kilometres driven reveals:

$$
y^{*}=1-d\left(1-\frac{d}{2}\right)
$$

We see that the degree of pollution abatement and the optimal volume of transport interact. Condition (0.4) states that, at the optimal number of kilometres, $y^{*}$, the marginal benefit of an additional kilometre, $1-y^{*}$

\footnotetext{
${ }^{4}$ Given the assumptions made, the objective function is strictly concave and hence the first order conditions are also sufficient. We also assume an interior solution.
} 
equals the marginal cost of supplying pollution abatement to society: i.e. a resource cost of $d^{2} / 2$ plus the remaining air pollution damage, $d(1-d)$ per kilometre, which in total equal $d(1-d / 2)$.

The choice of pollution abatement equipment minimises the social cost of driving a kilometre. In the absence of any pollution abatement, the cost to society of a kilometre comprises the full air pollution damages d. But this exceeds the cost to society with optimal technology: $d(1-d / 2)$. Therefore the optimal number of kilometres driven under optimal abatement technology, given by $(0.4)$, is greater than that under zero abatement, $y(0)=1-d$, derived by setting $\mathrm{z}=0$ in $(0.2)$.

\section{Choice of instruments}

In a market economy, the government cannot freely choose the two control variables. However, it may be able to decentralise the efficient outcome by using taxes or standards to alter the behaviour of drivers and car producers. We consider three types of pricing instruments: an emissions tax, an emissions reduction subsidy and a product (or per kilometre) tax, plus a non-pricing instrument - a technological standard. The government returns environmental tax revenues to consumers via a head tax ${ }^{5}$ such that tax revenues are merely a transfer to government rather than a resource cost. As a benchmark, however, we begin with the case in which government does not intervene at all.

\section{No intervention}

Competition requires producers to supply at minimum cost. Production cost, given by $z^{2} / 2$, is clearly minimised by setting $z^{N}=0$, where the superscript $\mathrm{N}$ denotes no intervention. The consumer price per kilometre is equal ${ }^{6}$ to $p^{N}=0$. In choosing the number of kilometres to drive, a consumer maximises:

$$
\int_{0}^{y}\left(1-x-p^{N}\right) d x
$$

with respect to $y$. Kilometres are consumed until the marginal benefit of a unit, 1-y, equals the consumer price:

$$
y^{N}=1-p^{N}=1>y^{*}
$$

In the absence of intervention, too many kilometres are consumed $\left(y^{N}>y^{*}\right)$ and emissions per kilometre are too high $\left(z^{N}=0<z^{*}\right)$. This corresponds to solution $p^{N}, y^{N}$ in Figure 1.

\section{Emissions Tax}

An emissions tax set equal to the marginal air pollution damages, $d$, per kilometre is sufficient to decentralise the efficient outcome, given by equations (0.3) and (0.4). Firstly, consider the behaviour of producers. We

\footnotetext{
5 This amounts to assuming that there are no other tax distortions in the economy. See section 4 below for some discussion of the case in which this assumption is relaxed.

${ }^{6}$ Recall this is the price net of a fixed resource cost.
} 
assume that producers pay an emission tax proportional to the emission rate of the car. In a perfectly competitive market and with constant returns to scale, the additional costs are all passed on to consumers. In choosing a level of pollution abatement equipment to install in a car, a producer must balance the additional resource cost of supplying abatement against the reduction in tax payments. Formally, the problem to be solved is to choose $\mathrm{z}$ to minimise unit production cost:

$$
t(1-z)+\frac{z^{2}}{2}
$$

Using the superscript $\mathrm{T}$ to denote the presence of an emissions tax, the first order condition requires that:

$$
z^{T}=t
$$

and thus, by setting $t=d$, the government ensures that the efficient level of pollution abatement is achieved, as given by (0.3). The producer price of a car kilometre is therefore given by

$$
\begin{aligned}
p^{T} & =d(1-d)+d^{2} / 2 \\
& =d(1-d / 2)
\end{aligned}
$$

Drivers consume kilometres until the marginal benefit equals the price, or:

$$
\begin{aligned}
y^{T} & =1-p^{T} \\
& =1-d(1-d / 2)
\end{aligned}
$$

where the second line follows from (0.8). Thus, the emissions tax results in the efficient number of kilometres driven, as given in (0.4). The consumer price is equal to the marginal social cost of a kilometre, measured at the optimal technology choice. This solution is illustrated in Figure 1 as solution $y^{T}, p^{T}$. The figure shows two shaded areas: one corresponding to the additional production cost of cars, due to cleaner technology, and the second shows the charges for the remaining environmental damage, which equals the collected tax revenue.

\section{Emissions Subsidy}

It is sometimes argued that a subsidy to cleaner equipment should be adopted. Clearly a subsidy for cleaner technology gives strong incentives for producers to adopt higher level of abatement. However, as we now show, a subsidy reduces the price of travel below marginal social cost, and thus induces consumers to drive too many kilometres.

Firstly, consider the producers' problem. The level of abatement is chosen to minimise unit production costs:

$$
\frac{z^{2}}{2}-s z
$$

Using the superscript $\mathrm{S}$ to denote the presence of an emission subsidy, the producer chooses a level of pollution abatement equipment by:

$$
z^{S}=s
$$

and hence, by setting $s=d$, the government can induce the efficient level of abatement in (0.3). Now consider the consumers' problem. As with a tax, consumers choose demand such that the marginal benefit of an additional kilometre, 1-y, is equal to the price, $p^{S}$. Crucially, however, the presence of the subsidy reduces the consumer price compared with a tax. Substituting (0.11) into (0.10) gives the consumer price as: 


$$
\begin{aligned}
p^{S} & =d^{2} / 2-d^{2} \\
& =-d^{2} / 2
\end{aligned}
$$

The consumer price is negative ${ }^{7}$ - and hence the optimal number of kilometres is chosen such that

$$
y^{S}=1+d^{2} / 2>y^{*}
$$

While the emissions subsidy induces an efficient level of investment in pollution abatement, it also induces an excessive number of kilometres to be driven. Although a better performing subsidy can be derived ${ }^{8}$, the basic inefficiency remains: a subsidy reduces the consumer price of car use and thus gives rise to too high a volume of transport activity.

\section{A Product tax (or kilometre tax)}

A product tax is a tax on each unit of the product independent of the production technology. In our setting this corresponds to a tax per car kilometre independent of the level of pollution abatement. Assume that the government sets the product tax at marginal air pollution damage, i.e. $t=d$. Producers have no incentive to invest in abatement and therefore set $z^{P}=0$ - where superscript $\mathrm{P}$ denotes the presence of the product tax. Consumers choose the level of demand such that marginal benefit, 1-y, equals the consumer price, $p^{P}$. But consumer price is given by $p^{P}=t=d$ and hence demand is given by:

$$
y^{P}=1-d<y^{*}
$$

The product tax can be set to induce drivers to choose the optimal number of kilometres, given a sub-optimal level of pollution abatement. This is seen from condition $(0.2)$, where $y(0)=1-d$. A product tax gives poor incentives to adopt efficient technology choices.

\section{Technological standard}

Finally, we consider a non-pricing instrument - a technological standard. Assume that the government decrees that cars must be manufactured with $z=d$. At this level, the marginal cost of pollution control equals the benefit of reduced air pollution. Producers comply and charge price $p^{S T}=d^{2} / 2$. Consumers drive until the marginal benefit of a trip equal the consumer price, giving:

$$
y^{S T}=1-d^{2} / 2>y^{*}
$$

The level of the technological standard is set optimally - the efficient level of abatement contained in condition (0.2) is achieved. However, the standard does not achieve the efficient volume of transport: $y^{S T}>y^{*}$. The consumer price only reflects the resource cost of the standard and not the marginal air pollution damage. As a result, car use remains underpriced, compared to the optimum, and excessive kilometres are driven.

\footnotetext{
${ }^{7}$ Recall that this price is net of any reference resource cost. Indeed, in Figure 1, we assume a strictly positive resource cost. ${ }^{8}$ The optimal subsidy is derived by maximising the net benefit function (0.1) subject to the constraints on the level of abatement investment given by (0.11) and on the demand for kilometres via the price function (0.12). Substituting these constraints gives a problem in s only. The solution, however, is not particularly transparent, although clearly the optimal level lies between 0 and $\mathrm{d}$. The same point applies to the product tax and the technology standard: we use arbitrary, though policy relevant levels of instruments to illustrate points that also apply with optimised levels.
} 


\section{Comparing instruments}

The impact of instruments is compared in Figure 1. Disregarding all implementation costs, an emissions tax (set at marginal external damage, d) is sufficient to decentralise the efficient outcome. All other instruments, both pricing and non-pricing, are inherently inefficient, or second-best.

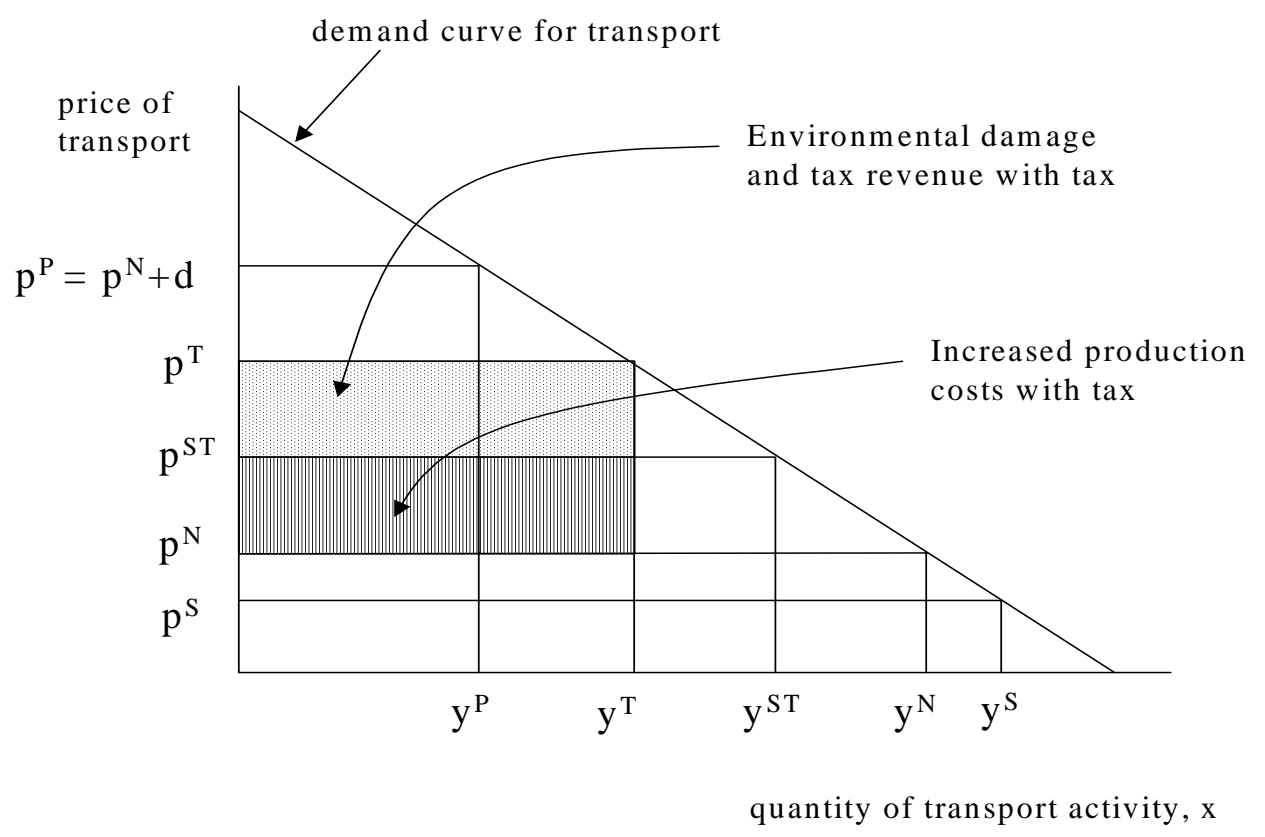

\section{Figure 1 Summary of Instruments}

It is natural to rank different policy instruments in terms of their degree of inefficiency. A comparison of instruments can be done on the basis of the benefit function given in (0.1). Indeed it is clear that the technology standard is more efficient than an emissions subsidy ${ }^{9}$ : both result in the same level of abatement, whilst the technology standard distorts demand less than the subsidy. However, the relative efficiency of the product tax is less straightforward to show, and hence, we provide numerical results in Table 1 based - in a somewhat 'back-of-the-envelope' manner - on the European urban car market ${ }^{10}$.

\footnotetext{
${ }^{9}$ Again, this refers only to the levels of instruments chosen in our example. Our analysis says nothing about the relative ranking of optimally set second-best instruments.

${ }^{10}$ The welfare assessment is computed from equation (0.1). In contrast to the text, we take a value of $\mathrm{c}$ in the cost function for abatement as 0.11 . We vary the value of air pollution damage from 0.05 to 0.15 . The optimal quantity of abatement is given by $z=d / c$, which assuming $\mathrm{d}=0.1$ and $\mathrm{c}=0.11$ gives $\mathrm{z}$ equal to 0.9 . It is thought that EU standards have abated as much as 90 per cent of air pollution, disregarding $\mathrm{CO}_{2}$ (ECMT, 2001).
} 
Table 1 Comparing the efficiency of instruments

\begin{tabular}{|l|c|c|c|}
\hline \multirow{2}{*}{} & \multicolumn{3}{|c|}{ Relative efficiency of instrument (tax = 100) } \\
\cline { 2 - 4 } & $\mathrm{d}=0.05$ & $\mathrm{~d}=0.1$ & $\mathrm{~d}=0.15$ \\
\hline Subsission & 93 & 89 & 61 \\
\hline Product Tax & 11 & 11 & 10 \\
\hline $\begin{array}{l}\text { Tech. } \\
\text { Standard }\end{array}$ & 97 & 99 & 99 \\
\hline
\end{tabular}

We assume that abatement technology is relatively cheap. Under efficient policy, and assuming a central case of $\mathrm{d}=0.1$, nearly 90 per cent of emissions are optimally abated. Therefore, as long as an instrument induces car producers to adopt such a high level of abatement, there is little welfare loss from failing to decentralise the optimal number of kilometres. The technology standard, for instance, requires 90 per cent of emissions to be abated. While the consumer price reflects the resource cost of meeting the standard, it fails to charge for air pollution damage. With 90 per cent reduction in emissions, and $\mathrm{d}=0.1$, air pollution damage is comparatively small. Thus the technology standard performs very well, almost as efficiently as the emissions tax - indeed, it is clear from Figure 1 that if environmental damage is small, $p^{S T}$ is only slightly smaller than $p^{T}$ and the resulting equilibrium is close to the optimal. In these circumstances the subsidy is also relatively efficient: it too results in a 90 per cent reduction in emissions, although, by reducing the consumer price, the final distortion on quantity of kilometres driven is higher than the standard. Indeed, the subsidy becomes relatively less efficient as the magnitude of the air pollution damage increases (compare $\mathrm{d}=0.15$ with $\mathrm{d}=0.05$ ). The relative efficiency of these instruments stands in stark contrast to a product tax. This instrument gives no incentive for installing pollution abatement equipment. The instrument performs badly in contrast to the others, resulting in only a mere 11 per cent of the efficiency gains of the tax.

Our model is extremely simple and and is somewhat biased against the use of pollution taxes. Pollution taxes perform in general best when there is a large variation in pollution reduction costs, whereas we analyse the case with homogenous polluters. A more realistic model would include heterogeneity in the car stock: cars with different mileage and age, different driving styles etc. In such a model, the advantage of pollution taxes over standards would be increased because taxes reduce pollution at minimal cost by equating the marginal emission reduction costs over polluters. A standard (that does not discriminate over polluters) cannot achieve this. One alternative to a standard is a system of tradable permits, which combines the properties of a pollution tax and a standard. For instance, a cap can be set on the total emissions of pollution, while manufacturers trade for rights to emit. Marginal emission reduction costs are equated between manufacturers.

One final point regarding standards. We have assumed that pollution abatement technology is fixed and known by all parties. But in the transport sector, where there has been rapid technological progress, this is 
debatable. Government may be tempted to try to force technology - that is set standards without knowing the feasibility or the cost of the measure. Examples include the CAFE standards in the US, the attempt by the European Commission to set fuel consumption at 5 litres per hundred kilometres for all new cars in 2005, the use in Calfornia of standards to achieve a market share of 5 per cent for zero emission cars (by 2002) or the attempt in 1970 by the US federal government to reduce emissions by 90 per cent in 1975. In each case, the regulator had to accept less ambitious targets. This is not surprising. Yao (1988) studies this problem in a two-period setting where the industry being regulated has more information on the effectiveness of $R \& D$ efforts. The regulator sets a standard for the first period, observes how difficult it is for the industry to comply, and then sets a further standard in the second period. The industry fears a ratchet effect: if they comply in the first period, they risk even stricter regulation in the second. It is optimal for the industry to under-invest in $R \& D$ in the first period in order to keep costs high.

\section{IMPLEMENTATION ISSUES}

Emissions taxes seems an attractive option for government. However, our model is in many respects too simplistic. We highlight two issues which may complicate policy advice: firstly, the technology for taxing on the basis of exhaust pipe emissions is unavailable, and secondly, even if it were, the damage from emissions is often site and time specific.

\section{Unavailability of Emissions Tax}

Recent technological advances in the measurement of vehicle emissions may justify consideration of an emission tax (Harrington et al., 1994). However, according to Fullerton and West (2002), the technology is currently neither cost-effective nor reliable in the sense that it cannot be tampered with by the owner. Policymakers must choose between combinations of imperfect instruments in a bid to mimic the efficient but unavailable tax on emissions. In a simple setting, combining instruments may still give the efficient outcome. For instance, in our model, combining a technology standard $(z=d)$ with a product tax $(t=d(1-d))$ perfectly mimics the efficient outcome ${ }^{11}$ of the emissions tax. The policy maker may also be able to tax inputs to the production of emissions: for instance, taxing fuels (gasoline, diesel) or vehicles.

Fullerton and West (2001) investigate this issue in a richer model than ours. Drivers choose the size of vehicle to buy, the amount of abatement technology to install, as well as the quantity and environmental quality of the fuel. The authors conclude that combinations of instruments (such as a tax on gasoline, a subsidy to abatement technology plus a tax on engine size) can only perfectly mimic the absent emissions tax in the restrictive case of identical individuals (or with individual-specific tax rates). In the realistic setting of heterogeneous consumers and uniform tax rates, combinations of instruments are less efficient that an emissions tax. In Fullerton and West (2000), the authors use data from the 1994 U.S. Consumer Expenditure Survey to calculate that an optimal combination of taxes on gasoline, size and vintage can achieve 71 per

\footnotetext{
${ }^{11}$ To see this, note that condition (0.3) is directly fulfilled, while the price of car use is given by $p=d(1-d)+d^{2} / 2$, which, after simple manipulation, gives condition (0.4).
} 
cent of the welfare gain of the missing emissions tax. A gasoline tax alone attains 62 per cent. Note that the authors assume only one externality - air pollution: see our comments on multiple distortions below.

Our model has abstracted from isssues of heterogeneous car stock. Yet given strict standards for new vehicles, emission rates from older vehicles can be some ten times greater than new. Scrapping policies ("cash for clunkers") appear - at least at first sight - an attractive means to tax older vehicles. But to determine the cost-effectiveness of such a policy, it is first necessary to construct the supply curve of emission reduction. Hahn (1995) analyses the various problems surrounding constructing this function. In particular he highlights a moral hazard problem: only the worst cars get scrapped which are hardly used anyway. Scrappage policies are likely to be effective only for a short period of time in urban areas, as, over time, the difference between emissions of old and new cars is likely to decrease. Moreover, better inspection and maintenance (I\&M) of cars (for instance via on-board diagnostics) may strongly reduce the costeffectiveness of scrappage policies. Alberini et al. (1995) examine empirically the participation rates in a scrappage scheme.

\section{Variability in air pollution damage}

We have assumed a constant marginal damage from air pollution, $d$. But this damage is likely to be very site and time specific, depending strongly on local micro-climatic features and population density. For instance, the formation of tropospheric ozone from emissions depends strongly on the presence of sunlight, temperature and the wind direction. Recent studies have shown that the same tonne of particulate matter can be ten times more damaging when emitted in central Paris than in rural France (Bickel et al., 1997).

Kolstad (1987) examines the use of uniform taxes when damage is variable. The optimal uniform tax is shown to depend on the relative slopes of the marginal abatement cost curve and the marginal damage curves. Uniform taxes can, in general, be either more or less efficient than a standard. However, a uniform emission fee does better to the extent that the marginal damage curves are relatively flat and the marginal cost function is relatively steep. There is no particular reason why this should be the case for transport markets. Indeed, applying this general theory to transport markets seems an interesting topic for future research.

\section{COMPARISON WITH MULTIPLE DISTORTIONS}

\section{Road congestion and air pollution}

We have thus far focused on a single type of environmental damage - air pollution. However, most policies designed to tackle air pollution have an additional impact on other distortions within the transport market, such as congestion, noise damage or accidents. Welfare analysis should therefore measure the impact of policy measures on a range of distortions rather than congestion or air pollution alone. 
In the urban car market, congestion is thought to be empirically the most significant external cost, at least in the peak-period. Table 2 reproduces estimates (from Proost and Van Dender (2001) - Table 3) of the peakperiod external cost of car use in Brussels for 2005 under current policy . Diesel cars have significantly higher air pollution costs than gasoline cars: this is due to emissions of small particulate matter, which have been linked to various human health problems.

Table 2 External costs from urban car use in Brussels in EURO per vehicle-km.

\begin{tabular}{|l|c|c|c|c|}
\hline \multirow{2}{*}{} & \multicolumn{2}{|c|}{ gasoline } & \multicolumn{2}{c|}{ diesel } \\
\cline { 2 - 5 } & peak & off-peak & peak & off-peak \\
\hline congestion & 1.856 & 0.003 & 1.856 & 0.003 \\
air pollution & 0.004 & 0.004 & 0.042 & 0.026 \\
accidents & 0.033 & 0.033 & 0.033 & 0.033 \\
noise & 0.002 & 0.008 & 0.002 & 0.008 \\
total & 1.895 & 0.047 & 1.932 & 0.068 \\
current tax & 0.12 & 0.11 & 0.08 & 0.07 \\
\hline
\end{tabular}

Our simple model can be extended to show how pricing policy should be adjusted to take account of congestion. Assume that the average time to travel a kilometre depends on total demand (y) in a smoothly convex fashion - to make things easy, assume a functional form, so that the time cost per kilometre is equal to $y^{2}$. The net benefit of transport can be adapted from equation $(0.1)$ to read:

$$
\int_{0}^{y}\left(1-x-d(1-z)-\frac{z^{2}}{2}-y^{2}\right) d x
$$

Maximising this expression with respect to the two available instruments shows that the efficient outcome is given by $z^{*}=d$, as in expression (0.3), while the optimal quantity is given by the implicit expression $y^{*}=1-d(1-d / 2)-3\left(y^{*}\right)^{2}$. The marginal benefit of a trip, 1-y, equals the marginal social cost: namely the resource cost of supplying the abatement technology, the cost of the remaining air pollution damage and the congestion cost. This last element differentiates the optimal quantity with expression (0.4). A road toll equal to the air pollution damage plus the external congestion cost - in this case $2 y^{2}$ decentralises the efficient outcome perfectly $^{12}$. Other instruments are less successful - for instance, the technology standard has no impact on congestion levels.

Proost and Van Dender (2001) examine the welfare gains from adopting different types of regulation, including both pricing measures and technology standards. This is done on the basis of a partial equilibrium model (TRENEN) of some 20 transport markets, calibrated to Brussels in 2005. These results are summarised in Table 3.

\footnotetext{
${ }^{12}$ The total time costs equal $y^{3}$ and thus the marginal cost of a kilometre equals $3 y^{2}$. The marginal external congestion cost is therefore equal to the marginal cost $3 y^{2}$ minus the private cost per kilometre, $y^{2}$, or $2 y^{2}$.
} 
Table 3 - Ranking efficiency of different instruments

\begin{tabular}{|l|c|}
\hline policy-choice & \% of possible welfare gain \\
\hline time varying cordon-pricing & 52 \\
\hline time invariant parking charges & 30 \\
\hline increased fuel tax & 5 \\
\hline higher technology standard & 0 \\
\hline subsidised abatement equipment & -2 \\
\hline
\end{tabular}

Source: Proost and Van Dender (2001) Tables 4 and 5 plus own manipulations.

A time varying cordon pricing scheme can - in a somewhat blunt manner - impose both a congestion charge and an emissions tax. It is therefore relatively efficient - achieving some 52 per cent of the welfare gains of a perfect charging system. Parking charges are assumed invariant with time and thus perform less well. A fuel tax gives some incentive for increasing the fuel efficiency of vehicles, but gives no incentive to alter the time of travel. The authors also consider a number of common policies targeted at air pollution. A higher technology standard (complying with Auto-Oil Scenario III $^{13}$ ) results in a negligible loss in welfare, while subsidising pollution abatement equipment results in a small loss in welfare.

The results of table 3 show that the ranking of instruments in the presence of multiple distortions can differ from that in the presence of a single distortion - air pollution - in Table 2. The fuel tax acts broadly as a product tax. When considering air pollution alone, the product tax performed relatively badly, as it resulted in too few kilometres being driven. In the presence of congestion (or other distortions), this may be beneficial. Hence in Table 3 the fuel tax is more efficient than the technology standard or the emissions subsidy, neither of which help alleviate congestion ${ }^{14}$.

Several authors have considered the welfare effect of congestion taxes in the presence of multiple-distortions (congestion, air pollution,, accidents etc). Recent examples include Parry and Bento (2002a) and Verhoef (2002), where the latter considers the spatial impact of various policies.

\section{Interactions between transport markets and distorted labour markets}

Policy reform may have impacts outside the transport sector. For instance, labour taxes distort the economy by subsidising leisure. Reforming the transport market, for example by introducting a commuting tax, may further exacerbate the labour market distortion. The general point stressed in the literature is that different instruments are likely, a priori, to exacerbate labour market distortions to a differing extent. Choices of both the level and type of instrument need to account for these impacts (Goulder et al., 1997; Goulder et al., 1999;

\footnotetext{
${ }^{13}$ Under this scenario, emissions reductions for gasoline cars in 2005 equal 65 per cent of 1996 levels for NOX and VOCs and 45 per cent for CO. The equivalent figures for diesel cars are 30 per cent and 50 per cent. In addition, PM is reduced by 50 per cent. See Proost and Van Dender, Appendix C for further details.

${ }^{14}$ It is also important to notice that Table 2 compares instruments to reduce air pollution assuming a baseline of zero abatement. In contrast, Table 3 has a baseline of current EU abatement standards for new vehicles, which, as referred to earlier, are thought to have reduced emissions by up to 90 per cent. It is perhaps not surprising, therefore, that further emissions reductions via a higher technological standard in Table 3 reduces welfare.
} 
Fullerton and Metcalf, 2001). In a transport context, Mayeres and Proost (1997) and (2001) examine optimal congestion taxes, and the reform of congestion taxes, in the presence of a distorted economy.

This literature also highlights that, in order to evaluate a particular policy, such as an air pollution tax, the analyst needs to consider how the revenue is spent. Intuitively, if the revenue from the tax is used to reduce distortive labour taxes, the net impact on the magnitude of the labour market distortion is smaller than if the revenue is handed back in a lump-sum manner. Parry and Bento (2001b) examine the welfare impact of a marginal increase in the congestion tax on peak-period urban traffic. They find that any positive tax on congestion is welfare reducing if the tax revenue is returned lump-sum. In contrast, a positive tax can increase welfare when used to reduce labour taxes.

\section{Equity impacts and institutional issues}

Our simple model in section 2 abstracts from distributional issues by assuming identical consumers. Our conclusions relate only to the efficiency properties of different instruments. Whilst this is clearly important, efficiency concerns cannot, in general, be separated from equity issues. Indeed, the very presence of a labour market tax in our previous section reflects equity concerns. There are several important distributional aspects to any policy reform. Firstly, how are different groups in society affected by the introduction of the environmental tax or technological standard? Secondly, who benefits from the cleaner environment? Thirdly, if the reform increases government revenues, who benefits from the recycling of the revenue? Policy evaluation requires detailed general equilibrium modelling to assess these effects.

Mayeres and Proost (1997) use an applied general equilibrium model to analyse optimal road tolls with 5 types of consumer, differing in labour productivity. The model is calibrated to the Belgian economy. The optimal level of the road toll is shown not to depend strongly on distributional concerns. This is because the initial tax system is assumed to pursue equity objectives in a more or less optimal way. However, the authors do not consider other instruments (subsidies, technological standards, a kilometre tax).

The model of section 2 also assumes that government is a benevolent, welfare-maximising institution. Recent economic literature has relaxed this assumption. Politicians' policy choices may be self-serving: maximising the probability of being re-elected, the revenues from a policy or minimise the work-load for the bureaucracy. Alternatively, a transport division may act to meet some ad-hoc criterion: maximising the number of trips whilst keeping average trip time or emissions below a certain level. Equally, local government may act to maximise welfare of local residents rather than the community as a whole. Environmental taxes may be set without taking into account effects on non-local consumers. However, nonlocals may provide an attractive source of tax revenue for the local community. We are not aware of research results on trying to explain government transport policy. However this seems a fruitful line of inquiry.

\section{CONCLUSIONS}


Economic theory makes a compelling case for using taxes to control the environmental side-effects of transportation. We have embedded this point in the debate over the control of air pollution from vehicles in Europe. Assuming cheap abatement technological and relatively small pollution damage, our numerical illustration stresses that instruments which give correct incentives for adopting pollution control equipment (taxes, subsidies or technological standards) perform significantly better than those which do not (the kilometre tax). The use of technological standards in Europe may have been a relatively efficient policy. the same theory applies when trying to solve both pollution and congestion problems. Pricing solutions (cordoncharges or parking charges) perform better than a kilometre tax or additional abatement standards.

The theory is sufficiently flexible that it applies to many other environmental issues in the transport sector. Take the case of airport noise damage. This can be reduced by installing abatement technology on planes (at higher resource cost) and by reducing the amount of air travel. This mirrors our air pollution problem of Section 2. Simple re-labelling of our model allows us to conclude that a noise tax gives correct incentives to invest in quieter aircraft and to reduce air travel. Depending on the costs of abatement and the magnitude of the damage, other pricing solutions (subsidies to abate, product tax on airline travel or technological standards) may perform relatively well or poorly in comparison with the efficient tax.

We have also stressed limitations in the theory. Taxing emissions may be difficult to implement, while heterogeneity in damages may complicate the choice of instrument. In addition, government is often trying to correct several distortions with one instrument (e.g. air pollution and congestion and labour market distortions). Careful analysis is required, often needing to account for effects outside of the transport sector. As is well-understood from the theory of the second-best, helping matters with respect to one distortion may produce adverse effects elsewhere.

Finally, we stress the need for a positive theory of transport policy. Despite clear efficicency advantages, environmental taxes are rarely adopted in the transport sector. This seems strange: if the efficiency gains are waiting to be enjoyed, why do politicians so rarely seem to pursue them?

\section{Acknowledgements}

Edward Calthrop is funded by grant G.0220.01 from the Funds for Scientific Research - Flanders (Belgium). Both authors would like to thank an anonymous referee for stimulating comments on an earlier draft. 


\section{REFERENCES}

Alberini, A., W.Harrington and V.McConnell (1995) Determinants of participation in accelerated vehicle retirement programs, RAND Journal of Economics, 26(1), 93-112..

Bickel, P., S. Schmid, W.Krewitt and R.Friedrich (eds) (1997) External Costs of Transport in ExternE, Final Report, Stuttgart:IER.

European Conference of Ministers of Transport (ECMT) (2001) Vehicle Emission Reductions, OECD/ECMT, Paris.

Fullerton, D. and G.Metcalf (2001), Environmental controls, scarcity rents, and pre-existing distortions, Journal of Public Economics, 80, 249-267.

Fullerton, D. and S.West (2002) Can Taxes on Cars and on Gasoline Mimic an Unavailable Tax on Emissions?, Journal of Environmental Economics and Management, 43, 135-157.

Fullerton, D. and S.West (2000) Tax and Subsidy Combinations for the Control of Car Pollution, NBER Working Paper No. 7774.

Goulder, L.H., I.W.H. Parry and D.Burtraw (1997) Revenue-raising versus other approaches to environmental protection: the critical significance of pre-existing tax distortions, RAND Journal of Economics, 28(4), 708-731.

Goulder, L.H., I.W.H. Parry, Roberton C.Williams and D.Burtraw (1999) The cost-effectiveness of alternative instruments for environmental protection in a second-best setting, Journal of Public Economics, 72, 329-360.

Hahn, R.W. (1995) An economic analysis of scrappage, RAND Journal of Economics, 26(2), 222-242.

Harrington, W., M. Walls and V.McConnell (1994) Shifting Gears: New Directions for Cars and Clean Air, Discussion Paper 94-26-REV, Resources for the Future, Washington.

Hensher, D.A. (2002) A Systematic Assessment of the Environmental Impacts of Transport Policy - An End Use Perspective, Environmental and Resource Economics, 22:185-217.

Kolstad, C. (1987) Uniformity vs. Differentiation in regulation externalities, Journal of Environmental Economics and Management, 14, 386-399.

Kolstad, C. (1999) Environmental Economics, Oxford University Press.

Parry, I.W.H. and A.Bento (2002a) Estimating the welfare effects of congestion taxes: the critical importance of other distortions within the transport system, Journal of Urban Economics, 51(2), 339-366.

Parry, I.W.H. and A.Bento (2002b), Revenue-recycling and the welfare effects of road pricing, Scandinavian Journal of Economics, 103(4), 645-671.

Mayeres, I. and S. Proost (1997) Optimal Tax and Public Investment Rules for Congestion Type of Externalities, Scandinavian Journal of Economics, 99(2), 261-279.

Mayeres, I and S.Proost (2001) Marginal tax reform, externalities and income distribution, Journal of Public Economics, 79, 343-363.

Proost, S. and K.Van Dender (2001) The welfare impacts of alternative policies to address atmospheric pollution in urban road transport, Regional Science and Urban Economics, 31, 383-411.

Verhoef, E.T. (2002) Second-best congestion pricing in general static transportation networks with elastic demands, Regional Science and Urban Economics, 32, 281-310. 
Yao, D.A. (1988) Strategic Responses to Automobile Emissions Control: A Game-Theoretic Analysis, Journal of Environmental Economics and Management, 15, 419-438. 
The Center for Economic Studies (CES) is the research division of the Department of Economics of the Katholieke Universiteit Leuven. The CES research department employs some 100 people. The division Energy, Transport \& Environment (ETE) currently consists of about 15 full time researchers. The general aim of ETE is to apply state of the art economic theory to current policy issues at the Flemish, Belgian and European level. An important asset of ETE is its extensive portfolio of numerical partial and general equilibrium models for the assessment of transport, energy and environmental policies.

\section{WORKING PAPER SERIES}

$n^{\circ} 2002-08$

$n^{\circ} 2002-07$

$n^{\circ} 2002-06$

$n^{\circ} 2002-05$

$n^{\circ} 2002-04$

$n^{\circ} 2002-03$

$\mathrm{n}^{\circ} 2002-02$

$n^{\circ} 2002-01$

$N^{\circ} 2001-26$

$n^{\circ} 2001-25$

$n^{\circ} 2001-24$

$n^{\circ} 2001-23$

$n^{\circ} 2001-22$

$n^{\circ} 2001-21$

$n^{\circ} 2001-20$

$n^{\circ} 2001-19$
Calthrop, E. Proost, S. (2002) Environmental Pricing in Transport Chapter for Handbook 4: Transport and the Environment

De Borger, B. and Van Dender, K. (2002), Transport tax reform, commuting and endogenous values of time

Franckx, L. and d'Amato, A. (2002), Multiple-task common agency with one fully-informed principal: implications for public policy

Moons, E. (2002), Cost- benefit analysis of the location of new forest land

Rousseau, S. and Proost, S. (2002), The Cost Effectiveness of Environmental Policy Instruments in the Presence of Imperfect Compliance

Calthrop, E. (2002), Evaluating on-street parking policy

Calthrop, E., and Proost, S. (2002), Regulating on-street parking

Franckx, L. (2002), Penalty and crime with lumpy choices: some further considerations

Rousseau, S. (2001), Effluent trading to improve water quality: what do we know today?

Degraeve, Z., Proost, S. and Wuyts, G. (2001), Cost-efficiency methodology for the selection of new car emission standards in Europe

Bigano, A. (2001), Environmental Dumping, Transboundary Pollution And Asymmetric Information - Some Insights For The Environmental Regulation Of The European Electricity Market

Mayeres, I., and Proost, S. (2001), Can we use transport accounts for pricing policy and distributional analysis?

Moons, E., Loomis, J., Proost, S., Eggermont, K. and Hermy, M. (2001), Travel cost and time measurement in travel cost models

Calthrop, E. (2001), Pricing a stock-constrained congestible facility

S. Proost, K. Van Dender, C. Courcelle, B. De Borger, J. Peirson, D. Sharp, R. Vickerman, E. Gibbons, M. O'Mahony, Q. Heaney, J. Van den Bergh, E. Verhoef (2001), How large is the gap between present and efficient transport prices in Europe?

Van Dender, K., and Proost, S. (2001), Optimal urban transport pricing with congestion and economies of density 